\title{
Paediatric liaison
}

\author{
Shirley A Leslie
}

This is the seventh in a series of articles in treatment of child psychiatric disorders.
The department of child psychiatry at Booth Hall Children's Hospital in north Manchester was founded in 1953. Although it has always been an integral part of the hospital, the fact that referrals came from a region of over four million people meant that sometimes referrals from the hospital had to take their place in a very long queue.

Over the years the service has changed, staff have developed new skills, but new problems have arisen. A paediatric liaison service must remain flexible and responsive to new challenges. In my view, the best advice that has been given is to 'be available, be practical, and be understandable'. 1

\section{Availability}

Being available meant that as a first priority the non-urgent outpatient waiting list was reduced to manageable proportions, even if that meant discouraging referrals from other districts, where there was a competent service, unless there was a definite request for a second opinion. One of my aims was, therefore, to encourage the development of district services throughout the region, even though this meant that the number of consultants in child psychiatry at Booth Hall remained the same throughout the years (1968-89) that I was there. With the knowledge that a non-urgent referral could be dealt with reasonably promptly, a paediatrician would not be tempted to admit a child for a spurious reason to circumvent the waiting list.

Another measure to increase availability was the provision of a rota, whereby a member of the junior staff and a social worker would be able to assess all children admitted with self poisoning within 24 hours of them regaining consciousness. Urgent requests for help with a diagnostic problem in a child, who was an inpatient, were responded to within 48 hours, by either a consultant or senior registrar. A summary of the essential findings and recommendations would be written in the paediatric casenotes immediately after the assessment.

The apparent availability of the child psychiatrists was heightened by taking an active part in the division of paediatrics, attending paediatric postgraduate meetings and by the simple, but effective, measure of having lunch with the other members of the medical staff.

Family Psychiatry, Booth Hall Children's

Hospital,

Charlestown Road, Blackley,

Manchester M9 2AA

Correspondence to: Dr Leslie.
The way in which a paediatric liaison service is organised is liable to vary with the personal interests and expertise of the child psychiatrists concerned, and what is practicable in a given situation. There were several requests for combined ward rounds and joint clinics, but in the early years this was rarely done, mainly on account of pressure of time.

LIMITED INVOLVEMENT IN CHILD ABUSE

At the beginning of the 1970s a decision was made not to get very involved in the management and treatment of families where there was suspected child abuse. At the time, the National Society for the Prevention of Cruelty to Children had set up a special unit in Manchester to offer a comprehensive service to these families and it was thought that they would be able to offer more than we were able to. This was obviously different from the decision made in Oxford. ${ }^{2}$ The rise in the recognition of sexual abuse in the 1980 s and the increase in referrals of children with emotional and behavioural problems, where abuse was an important factor, forced us to reconsider this decision.

\section{SELF POISONING IN ADOLESCENTS}

The sharp rise in the number of children admitted with self poisoning, during the 1970 s, left us with no option but to respond promptly and effectively. It was our policy that no child should leave the hospital without themselves being seen by the doctor, who would be responsible for following them up. A member of the child's family would also be seen, before discharge, in order to encourage future involvement with the child psychiatric team if this was thought to be necessary. ${ }^{3}$

\section{RESPONDING TO CHANGING NEEDS AND} EXPECTATIONS

Between these extremes of full involvement in what is commonly regarded as the true province of the psychiatrist, as with attempted suicide, and disengagement from what could be seen as exclusively the province of the social worker and paediatrician, as with physical child abuse, there remained the decision as to how best to respond to other requests for help. These were mainly requests for assistance with the diagnosis of a sick child, help in the management of the common disorders of childhood, which are known to have a psychological component, and referrals of children with prolonged and sometimes disabling disorders such as epilepsy, diabetes, asthma, and cystic fibrosis.

Staff on the burns and neurosurgical units also needed support and guidance in the best ways to help families whose child had been 
severely injured. Likewise, at a later stage, staff on the intensive care unit felt in need of training as how best to cope with their own feelings about being constantly in touch with dying children and their families.

The child psychiatrist needed to be able to provide help to the individual child and to his or her carers. There was also a need to teach staff how to recognise a psychological problem and how to become more aware of their own reactions in stressful situations.

Paediatricians and their supporting staff needed to know how to handle a referral to a child psychiatrist or psychologist and how to improve their ability to treat common problems, so that some referrals may be no longer necessary.

\section{Requests for help with diagnosis \\ THE REFERRAL PROCESS}

Referrals for help with a diagnosis remained the principal component of our liaison service. This type of referral is best carried out at senior level and it is essential that the paediatrician or their senior registrar have discussed the referral with the parents and the child, if old enough, beforehand.

Psychiatry still caries a stigma in the mind of the average person and it is here that the paediatrician's trust in the psychiatrist to whom he or she is going to refer is vital. An explanation that anxieties can sometimes give rise to pain that is genuinely felt should dispel the notion that the child is thought to be a liar or a fraud.

Similarly it is important to help parents to see that referral to a child psychiatrist does not necessarily mean that their child is mentally ill or that the report will form part of a child's school record. As far as the child is concerned, the doctor is one who talks to children about worries and problems. Children are encouraged to know that no painful procedures, such as injections, will be given.

\section{THE PSYCHIATRIC ASSESSMENT}

The process of psychiatric interviewing is of necessity detailed and should not be rushed. As well as one or two interviews with the child, there must be at least one with a parent, preferably both. Psychiatrists are trained to make a positive psychiatric diagnosis and not to rely solely on the absence of physiological signs. With children, this will mean an understanding of the dynamics of the family and whether or not a symptom is being used for a secondary gain. ${ }^{4}$

Prompt and confident psychiatric diagnosis may spare a child unnecessary investigative procedures and shorten the period of disability. ${ }^{6}$ When the issues are less clear, paediatrician and child psychiatrist may continue to work closely together, perhaps during an inpatient assessment, either in a paediatric ward or in a child psychiatric inpatient unit.

\section{Requests for help with common disorders} ENURESIS

Referrals of children with enuresis, encopresis, and sleep disorders were very common 20 years ago. The improvements in available treatment techniques have meant that only the most intractable now reach a child psychiatric clinic. Children with enuresis, who are thought not to have a physical problem, are either dealt with in primary care or their treatment programme is supervised by a clinical psychologist. This is entirely appropriate as children with monosymptomatic enuresis should not be considered to have a psychiatric disorder. ${ }^{7}$

\section{ENCOPRESIS}

Encopresis, which is not associated with any physical disorder, is sometimes associated with other behaviour problems and may warrant a full psychiatric assessment. Nevertheless, many cases can be dealt with symptomatically, especially those thought to be due to the withholding of faeces, for whatever reason. Behavioural treatments have proved the most effective and can be administered by a psychologist or a suitably trained community nurse, though most studies have shown that a prolonged follow up is essential. ${ }^{8}$

\section{SLEEPING PROBLEMS}

The improvement in methods of helping the parents of young children with sleeping problems ${ }^{9}$ has meant that health visitors now feel more competent to treat these disorders in primary care. In some areas sleep clinics have been established to give support and advice to parents with unusually fretful and wakeful children.

One of my priorities over the years was to help health visitors to understand the factors that often underlie some of the common behavioural problems in young children and some basic principles for tackling them. ${ }^{10}$

\section{Children with disabling disorders}

The referral of children who are having a particular problem in coming to terms with some aspect of a chronic illness or handicap is often an appropriate referral to a child psychiatric service. For instance the presence of family conflict and dissatisfaction on the part of the mother with her marriage has been shown to relate to poor diabetic control in the child. ${ }^{11}$ Likewise, family problems may exacerbate the severity of symptoms in some asthmatic children. ${ }^{12}$

Adolescents also become extremely sensitive about physical disfigurements that previously they had seemed to take in their stride. Similar problems are experienced by epileptic children. The problems may manifest themselves in different ways: depression, school avoidance, or behavioural change. Much will depend on what significance the disease process or handicap has for the child and his or her family..$^{1314}$

Although services now exist for most of these groups, providing peer support for children and their parents, some children benefit from individual supportive psychotherapy and others from family therapy. Most can be dealt with in 
the main outpatient service. Joint clinics can be helpful, especially if a clinic is set aside where patients, who both a paediatrician and child psychiatrist have in common, can be seen together, but we did not have these very often.

\section{Services to regional specialist units}

At Booth Hall there are regional services for the treatment of burns, a renal dialysis unit, and departments of neurosurgery and neurology. Because of the severity of the children's problems and the way in which their behaviours often caused a great deal of anxiety to the nursing staff, these units were the first to demand, and for some of the time to get, their own direct liaison with either a child psychiatrist or a clinical psychologist.

\section{BURNS UNIT}

The direct liaison provided by a clinical psychologist to the burns unit enabled the staff to see the trauma as affecting the whole family and not only the child patient. Supporting the family with the feelings of guilt and helplessness was as important as encouraging the child to come to terms with their disfigurement. ${ }^{15}$ Referrals to the child psychiatrist would then only be made when a child was severely behaviourally disturbed, in a toxic confusional state, or unusually depressed and withdrawn.

\section{NEUROSURGICAL UNIT}

Similarly, the neurosurgical unit had a clinical psychologist with a sessional attachment, which meant that the common sequelae of children with head injuries were clearly understood by the staff and the expected difficulties communicated to both the parents and the child's school teachers on discharge. The children who were referred on to our department usually had very severe injuries and a pre-existing psychiatric disorder.

\section{RENAL UNIT}

My colleague Elena Garralda undertook to have a liaison role with the renal unit. She was able to attend ward meetings and became a significant member of the team. Psychiatric assessment of the children showed that more definite psychological difficulties occurred in those children with the most severe illness. However, psychiatric disturbance was again related to stress in the family and compliance with drug treatment. ${ }^{16}$

\section{NEUROLOGY UNIT}

A major part of our liaison work was in the neurology department. It became common practice for the neurologist to discuss a case with one of us, before admission, when a combined assessment was thought to be important. The agreement of suitable dates for the child's admission was then possible. Frequently such patients were treated jointly on the medical ward. ${ }^{17}$
FOLLOW UP

Most of these referrals from the specialist units involved children who lived outside the district. Follow up was therefore sometimes difficult, though parents were often prepared to travel considerable distances at their own expense. It was, however, rarely thought appropriate to refer children to the local child psychiatric service when they had not been involved in any of the inpatient treatment. We suspect that such referrals would not have been taken up by the families. This has major staffing implications for specialised teaching units who wish to encourage a closer child psychiatric liaison.

\section{Teaching}

The essence of good teaching is to make the subject understandable. Psychiatrists are well known for using jargon only understood by the initiated. Writing reports and letters in a way that makes sense to the average intelligent doctor is a good way of teaching one's subject and should not be underestimated. Whenever possible our department's assessment and recommendations for treatment would be put in letter form addressed to the paediatrician or relevant consultant and a copy sent to the family doctor.

\section{POSTGRADUATE}

Attending clinical meetings and participating in postgraduate training in paediatrics was a regular part of our work. Our monthly child psychiatric case conference was held in the postgraduate centre and was available to all. From time to time we were also able to suggest speakers for day conferences on such themes as the care of the dying child.

\section{UNDERGRADUATE}

The clinical teaching of child psychiatry to undergraduates took place in their paediatric placement. ${ }^{18}$ As well as attending outpatient clinics and seeing videotaped interviews with child psychiatric patients they also attended weekly seminars, taken by the senior staff, in which they were asked to present cases they had seen. Four of the students would be asked to present a paediatric case from a psychosocial point of view. Most had difficulty with the concept at first, as they had the patients neatly compartmentalised into paediatric and psychiatric.

The aim was to help them to look at such issues as to how a family with a child with a life threatening disease copes or why a baby with a chest infection has not been visited. Sometimes the group would be stimulated to look at deeper issues as to how they felt about the death of a child and how they would help a family come to terms with the birth of a handicapped child.

\section{Conclusion}

This account of the development of a paediatric liaison service to a specialist children's hospital in north Manchester does not detail every kind 
of case we saw. We estimated that approximately $25 \%$ of our referrals came from our own hospital. Because of our commitments to more than one district service and a supradistrict child psychiatric inpatient unit our services were inevitably stretched.

As the service developed it has been possible for clinical psychologists to take on the direct liaison with some specialist units, thereby helping the nursing staff to have a better understanding of the emotional and behavioural problems of their patients. Likewise the outcome of a regular clinic between one of the paediatric surgeons and a child psychiatrist was the establishment of a district nursing service for children with encopresis. It is essential that in this type of service all disciplines can refer to each other and that communication between them is easy. The welfare of the child is more important than keeping to rigid professional boundaries. To a large extent a service will develop according to the resources available.

There are many advantages to child psychiatrists in being part of a paediatric service. We were kept up to date in the paediatric field and we hope that the frequent exposure to their influence and scientific rigour prevented us from becoming too set in our ways or inclined to make extravagant claims for our specialty.

In return, we hope that they have gained from our insistence on seeing the child and his or her disease or handicap in the context of their level of understanding, and their life experience, and their family situation. As our knowledge base has increased, and treatment techniques have become more specific, we hope that a basic understanding of our specialty will be a part of every paediatrician's training.

1 Rothenberg MB. Child pisychiatry-pediatric consultationliaison services in the hospital setting. Gen Hosp Psychiatry 1979;1:281-6.

2 Lynch M, Robertson J. Consequences of child abuse. London: Academic Press, 1982.

3 Kerfoot $M$. Deliberate self poisoning in childhood and early adolescence. $\mathcal{F}$ Child Psychol Psychiatry 1988;29:335-44.

4 Stone FH. Psychiatry and the paediatrician. London: Butterworths, 1976:19-32.

5 Mrazek D. Child psychiatric consultation and liaison to paediatrics. In: Rutter $\mathbf{M}$, Hersov $\mathrm{L}$, eds. Child and adolescent psychiatry. Modern approaches. Oxford: Blackwell, 1985:888-9.

6 Dubowitz V, Hersov L. Management of children with nonorganic (hysterical) disorders of motor function. Dev Med Child Neurol 1976;18:358-68.

7 Graham P. Enuresis: a child psychiatrist's approach. In: Kolvin I, MacKeith RC, Meadow SR, eds. Bladder control and enuresis. Clinics in developmental medicine 48/49. London: and enuresis. Clinics in developmental medicine 48/49. London: 1973:276-80.

8 Hersov L. Faecal soiling. In: Rutter M, Hersov L, eds. Child and adolescent psychiatry. Modern approaches. Oxford: Blackwell, 1985:482-9.

9 Douglas J, Richman N. My child won't sleep. Harmondsworth: Penguin Handbooks, 1984 .

10 Lask B. Children's problems. A parent's guide to understanding and tackling them. London: Dunitz, 1985

11 Marteau TM, Bloch S, Baum JD. Family life and diabetic control. F Child Psychol Psychiatry 1987;28:823-34.

12 Mrazek DA. Childhood asthma: two central questions for child psychiatry. F Child Psychol Psychiatry 1986;27: $1-5$.

13 Taylor DC. The components of sickness: diseases illnesses and predicaments. In: Apley J, Ounsted C, eds. One child. London: Heinemann/Spastics International Medical London: Heinemann/Spas

14 Hoare J. Children with epilepsy and their families. $f$ Child Psychol Psychiatry 1987;28:651-5.

15 Rivlin E. The psychological trauma and management of severe burns in children and adolescents. Br F Hosp Med 1988;40:210-5.

16 Garralda ME, Jameson RA, Reynolds JM, Postlethwaite RJ. Psychiatric adjustment in children with chronic renal failure. 7 Child Psychol Psychiatry 1988;29:79-90.

17 Leslie SA. The diagnosis and treatment of hysterical conversion reactions. Arch Dis Child 1988;63:506-11.

18 Garralda ME. Teaching child psychiatry to medical students: students feedback. Psychiatric Bulletin 1984;8:171-2. 